\title{
MicroRNA response to hypoxic stress in soft tissue sarcoma cells: microRNA mediated regulation of HIF3a
}

Caroline MM Gits', Patricia F van Kuijkํ, Jonneke CWM de Rijck', Nikky Muskens', Moniek BE Jonkers', Wilfred F van IJcken², Ron HJ Mathijssen', Jaap Verweij', Stefan Sleijfer ${ }^{1}$ and Erik AC Wiemer ${ }^{1,3^{*}}$

\begin{abstract}
Background: Hypoxia is often encountered in solid tumors and known to contribute to aggressive tumor behavior, radiation- and chemotherapy resistance resulting in a poor prognosis for the cancer patient. MicroRNAs (miRNAs) play a role in the regulation of the tumor cell response to hypoxia, however, not much is known about the involvement of miRNAs in hypoxic signalling pathways in soft tissue sarcomas (STS).

Method: A panel of twelve STS cell lines was exposed to atmospheric oxygen concentrations (normoxia) or 1\% oxygen (hypoxia) for up to $48 \mathrm{~h}$. Hypoxic conditions were verified and miRNA expression profiles were assessed by LNA ${ }^{\mathrm{TM}}$ oligonucleotide microarrays and RT-PCR after $24 \mathrm{~h}$. The expression of target genes regulated by hypoxia responsive miRNAs is examined by end-point PCR and validated by luciferase reporter constructs.

Results: Exposure of STS cell lines to hypoxic conditions gave rise to upregulation of Hypoxia Inducible Factor (HIF) 1a protein levels and increased mRNA expression of HIF1 target genes CA9 and VEGFA. Deregulation of miRNA expression after $24 \mathrm{~h}$ of hypoxia was observed. The most differentially expressed miRNAs $(p<0.001)$ in response to hypoxia were miR-185-3p, miR-485-5p, miR-216a-5p (upregulated) and miR-625-5p (downregulated). The well-known hypoxia responsive miR-210-3p could not be reliably detected by the microarray platform most likely for technical reasons, however, its upregulation upon hypoxic stress was apparent by qPCR. Target prediction algorithms identified 11 potential binding sites for miR-485-5p and a single putative miR-210-3p binding site in the $3^{\prime}$ UTR of HIF3a, the least studied member of the HIF family. We showed that HIF3a transcripts, expressing a $3^{\prime} U T R$ containing the miR-485-5p and miR-210-3p target sites, are expressed in all sarcoma cell lines and upregulated upon hypoxia. Additionally, luciferase reporter constructs containing the $3^{\prime} \mathrm{UTR}$ of HIF3a were used to demonstrate regulation of HIF3a by miR-210-3p and miR-485-5p.
\end{abstract}

Conclusion: Here we provide evidence for the miRNA mediated regulation of HIF3a by hypoxia responsive miRNAs in STS, which may help to tightly regulate and fine-tune the hypoxic response. This provides a better insight into the mechanisms underlying the hypoxic response in STS and may ultimately yield information on novel prognostic and predictive markers or targets for treatment.

Keywords: miRNA, Hypoxia, HIF3a, Soft tissue sarcomas, miR-210-3p, miR-485-5p

\footnotetext{
* Correspondence: e.wiemer@erasmusmc.nl

'Department of Medical Oncology, Erasmus University Medical Center -

Erasmus MC Cancer Institute, Rotterdam, the Netherlands

${ }^{3}$ Department of Medical Oncology, Erasmus MC Cancer Institute, Erasmus

University Medical Center, Rm Be422, Wytemaweg 80, 3015 CN Rotterdam,

the Netherlands

Full list of author information is available at the end of the article
}

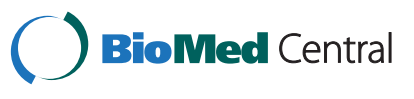

(C) 2014 Gits et al.; licensee BioMed Central Ltd. This is an Open Access article distributed under the terms of the Creative Commons Attribution License (http://creativecommons.org/licenses/by/2.0), which permits unrestricted use, distribution, and reproduction in any medium, provided the original work is properly credited. The Creative Commons Public Domain Dedication waiver (http://creativecommons.org/publicdomain/zero/1.0/) applies to the data made available in this article, unless otherwise stated. 


\section{Background}

Hypoxia is a condition of reduced oxygen tension that is often encountered in solid tumors including soft tissue sarcomas (STS) when they outgrow their blood supply. The tumor cells respond to the hypoxic conditions by inducing genes that regulate various biological processes including cellular proliferation, apoptosis, metabolism, angiogenesis and migration [1]. A key element in the response to hypoxia is the upregulation of HIF1, a member of the family of hypoxia inducible factors (HIFs) also comprising HIF2 and HIF3 [2]. These transcription factors consist of a tightly controlled alpha (HIF $\alpha$ ), and a constitutively activated beta subunit (HIF $\beta$ or ARNT family). Upon hypoxia, the alpha subunit is stabilized, translocated to the nucleus, where it dimerizes to the beta subunit. The HIF complex binds to hypoxia responsive elements (HREs) in gene promoters, thereby inducing the transcription of genes important for the adaption to low oxygen concentrations. HIF $1 \alpha$ and HIF $2 \alpha$ have similar protein domain structures, are regulated in a similar fashion and share several target genes [3], although their expression patterns differ in some tissues and some unique target genes have been identified [4]. The function(s) of HIF3 $\alpha$ and the way it is regulated are still largely unknown. Complicating the study of HIF $3 \alpha$ is the fact that alternative splice variants are recognized coding for at least six isoforms, with structural and functional differences [5-7]. HIF3 $\alpha$ is regulated by HIF1 at the transcriptional level and exerts an inhibitory effect on HIF1 $\alpha$ or HIF-dependent gene regulation, in a cell-type specific manner [5-11].

Tumor hypoxia and the accompanying biochemical and cellular changes in the tumor cells contribute to aggressive tumor behavior, and radiation- and chemotherapy resistance in many tumor types, including STS $[12,13]$. STS is a group of relatively rare tumors of mesenchymal origin in which currently more than 50 different histological subtypes are recognized. STS have been reported to present with hypoxic areas resulting in increased tumor proliferation, distant metastases and shorter overall disease survival $[14,15]$. Given the poor prognosis STS patients face with, a median overall survival of only 1 year for patients presenting with metastatic disease, more insight is needed into the effects of hypoxia in STS and how hypoxia is regulated in STS.

MicroRNAs (miRNAs) are small ( $\sim 23 \mathrm{nt})$ non-protein coding RNA molecules that negatively regulate gene expression. MiRNAs play essential roles in a wide variety of cellular processes, such as differentiation, cell cycle regulation, metabolism, apoptosis and stem cell maintenance and are associated with various diseases including cancer [16]. Most cancers display a deregulated miRNA expression profile when compared to relevant normal tissues. Some miRNAs may function as an
oncomiR, having either a tumor suppressive or an oncogenic role [17-20]. MiRNA expression can be influenced by changes in the tumor microenvironment $[21,22]$ including conditions like tumor hypoxia [23-26]. The miRNA response to hypoxia, which is often cell-type specific, suggests miRNAs are intimately involved in the cellular reaction to hypoxia $[23,24,26]$ and some are in turn involved in feedback mechanisms that regulate HIF [27-32]. Interestingly, many hypoxia responsive miRNAs (HRMs) are also upregulated in cancer suggesting they also function in tumorigenesis and/or tumor progression [26]. As opposed to the role of HRMs in the major cancer types relatively little is known about the role of hypoxic miRNAs in STS. In this study, we describe the miRNA response to hypoxic stress in sarcoma cell lines revealing the involvement of miRNAs in the hypoxic signalling in STS.

\section{Methods}

\section{Cell culture}

A panel of 12 soft tissue sarcoma cell lines was used, consisting of the fibrosarcoma cell lines HT1080, SW684 and BG-8, the liposarcoma cell line SW872, the leiomyosarcoma cell lines SK-UT-1 and SK-LMS-1, the synovial sarcoma cell line SW982 and the rhabdomyosarcoma cell lines RH30, A204, A673, RD and SJCRH30. Note that the A673 (ATCC ${ }^{\circ} \mathrm{CRL}-1598$ ) cell line is now listed on the ATCC website as Ewing sarcoma. The myxoid fibrosarcoma cell line BG-8 was a kind gift from Dr. A. Carnero (Centro Nacional de Investigaciones Oncológicas, Madrid, Spain); HT1080, SK-UT-1, RD and RH-30 were acquired from Dr. M. Debiec-Rychter (KU Leuven, Leuven, Belgium) and SJCRH30 was obtained from Dr. L. Alberti (Université de Lyon, Centre Léon Bérard, Lyon, France). All further cell lines were obtained from the ATCC, Rockville, MD, USA. The cell lines were cultured in RPMI 1640/GlutaMAX (Invitrogen, Bleiswijk, The Netherlands) supplemented with $10 \%$ fetal bovine serum, at $37^{\circ} \mathrm{C}, 5 \% \mathrm{CO}_{2}$.

\section{Hypoxic experiments}

The 12 cell lines comprising the soft tissue sarcoma panel were cultured under standard conditions and seeded in 6 well culture plates or $9 \mathrm{~cm}$ cell culture dishes (miRNA profiling experiment) in duplicate at such a cell density that $50 \%$ confluency was reached after $48 \mathrm{~h}$. Subsequently half of the culture plates was kept under standard, normoxic $\left(21 \% \mathrm{O}_{2}\right)$ culture conditions whereas the other half was transferred to a hypoxic incubator and cultured at $37^{\circ} \mathrm{C}, 5 \% \mathrm{CO}_{2}, 1 \% \mathrm{O}_{2}$ for $6 \mathrm{~h}$ to $48 \mathrm{~h}$ as indicated. After the appropriate normoxic/ hypoxic incubation period cells were rapidly washed with ice-cold PBS after which total RNA was isolated 
(three separate wells $/ 9 \mathrm{~cm}$ dish) and total protein lysates (three separate wells) were prepared.

\section{RNA isolation}

Total RNA was isolated using RNAbee (Tel Test Inc., Friendswood, TX, USA) according to the manufacturer's recommendation. The RNA concentration and quality were determined on a Nanodrop-1000 (Nanodrop Technologies, Wilmington, DE, USA).

\section{MiRNA microarray}

MiRNA profiling was performed essentially as previously described [33]. In brief, $1 \mu \mathrm{g}$ total RNA was fluorescently labeled with Cy3 using the ULS $^{\text {тм }}$ aRNA Labeling Kit (Kreatech Diagnostics, Amsterdam, The Netherlands). Labeled RNA was hybridized with locked nucleic acid $\left(\mathrm{LNA}^{\mathrm{TM}}\right)$ modified oligonucleotide capture probes (Exiqon) spotted in duplicate on Nexterion E slides. The capture probe set (based on miRBase version 10, annotation version 13) contains 1344 probes of which 725 are capable of detecting human miRNAs. Hybridized slides were scanned and median spot intensity was determined using ImaGene software (BioDiscovery Inc., Hawthorne, CA, USA). After background subtraction, expression values were quantile normalized using $R$ software (http://cran.r-project.org; version 2.15.2, release oct. 2012), low expressed miRNAs and obvious outliers/bad spots were removed, and duplicate spots were averaged. Outliers/bad spots were identified by determining the average expression value of each miRNA and examining whether duplicate spots differ from the average $(>2 \times$ greater or $>5 \times$ smaller). Flagged spots were checked by eye to determine why the signal is aberrant e.g. a speck of dust or printing error. Only in case of an apparent technical error, noted in less than $1 \%$ of the spots, a spot was discarded. For each expression value, the ratio to the geometric mean of the samples was log2 transformed. These values were used to determine differentially expressed miRNAs. Hierarchical clustering analyses were performed in Spotfire (Spotfire DecisionSite 9.1, Tibco Software, Somerville, MA. USA).

\section{qPCR analysis of miRNA}

MiR-210-3p expression was examined using TaqMan ${ }^{\circledR}$ MicroRNA Assays (Applied Biosystems, Nieuwerkerk aan den IJssel, The Netherlands). In brief, total RNA (50 ng) was reverse transcribed using specific miRNA primers and the TaqMan ${ }^{\circledR}$ MicroRNA Reverse Transcription Kit (Applied Biosystems). The resulting cDNA was used as input in a quantitative real-time PCR (qPCR) using the miRNA specific primer/probe mix together with the TaqMan ${ }^{\circledR}$ Universal PCR Master Mix No AmpErase ${ }^{\bullet}$ UNG (Applied Biosystems) according to manufacturer's protocol. qPCR data were analyzed with
SDS software (version 2.4, Applied Biosystems). MiRNA expression was normalized using RNU43 expression and the comparative $\mathrm{C}_{\mathrm{T}}$-method [34].

\section{cDNA-synthesis}

RNA (1 $\mu \mathrm{g}$ ) was reversed transcribed using the High Capacity cDNA Reverse Transcription Kit (Applied Biosystems) according to the manufacturer's protocol. The resulting cDNA was used to perform qPCR and endpoint PCR analysis.

\section{qPCR analysis of mRNAs}

cDNA (45 ng) was used to perform qPCR using the primer/probe mix from the TaqMan ${ }^{\circledR}$ Gene Expression Assays of human VEGFA (assay ID Hs00900055_m1) and CA9 (assay ID Hs00154208_m1) with exon spanning probes, and TaqMan ${ }^{\circledR}$ Universal PCR Master Mix using the 7500 Fast Real-Time PCR system (all Applied Biosystems) according to the manufacturer's protocol. HPRT was used as a housekeeper gene for normalization purposes using the comparative $\mathrm{C}_{\mathrm{T}}$-method. qPCR data was analyzed with SDS software (Applied Biosystems).

\section{End-point PCR analysis}

cDNA (50 ng) was used to perform endpoint PCR using $1 \times$ Green Go Taq Flexi Buffer, 1.25U Go Taq Flexi polymerase, $200 \mu \mathrm{M}$ dNTP mix, $1.5 \mathrm{mM} \mathrm{MgCl}_{2}$ and $300 \mathrm{nM}$ forward and reverse primer of HIF3 $\alpha$ (Additional file 1: Table S1a) on a thermal cycler using the following PCRprogram: $2 \min 95^{\circ} \mathrm{C}, 30-40$ cycles of $\left(45 \mathrm{sec} 95^{\circ} \mathrm{C}\right.$, $45 \mathrm{sec} 60-65^{\circ} \mathrm{C}, 45 \mathrm{sec} 72^{\circ} \mathrm{C}$ ), 5 min $72^{\circ} \mathrm{C}$. PCR-products were analyzed on a $1.5 \%$ agarose gel in $0.5 \times$ TBE buffer with $0.5 \mu \mathrm{g} / \mathrm{ml}$ ethidium bromide.

\section{Protein extraction}

Cells were harvested in MCB lysis buffer (50 mM Tris$\mathrm{HCl} \mathrm{pH} 7.5,50 \mathrm{mM} \mathrm{NaCl}, 10 \%$ glycerol, 1\% NP-40, 0.5\% Na-deoxycholate, $20 \mathrm{mM} \mathrm{NaF}$ ) supplemented with a cocktail of protease and phosphatase inhibitors. Lysates were thoroughly vortexed and further lysed by two subsequent freeze-thaw cycles using liquid nitrogen. Cell debris was spun down and protein concentration was determined by a Bradford assay (BioRad, Veenendaal, The Netherlands).

\section{Western blotting}

Twenty $\mu \mathrm{g}$ of total protein was subjected to SDS-PAGE. Proteins were transferred to a PVDF membrane followed by blocking of the membrane in $5 \%$ non-fat dry milk in PBS-Tween (Phosphate buffered saline, 0.05\% (v/v) Tween 20) to prevent non-specific antibody binding. Primary and secondary antibody incubations were carried out in the same buffer using anti-HIF1 $\alpha$ (610958, mouse monoclonal, 1:500, BD Biosciences, Breda, The Netherlands), anti- 
HIF3 $\alpha$ (ab10134, rabbit polyclonal, 1:500, Abcam, Cambridge, UK) and anti- $\beta$-Actin (AC-15, mouse monoclonal, 1:5000, Sigma-Aldrich, Zwijndrecht, The Netherlands) as a loading control. As secondary antibody HRPconjugated goat-anti-mouse (1:10000, Santa Cruz Biotechnology, Heidelberg, Germany) or goat-anti-rabbit (1:10000, Jackson Immunoresearch, Suffolk, UK) antibodies were used. Antibody incubations were followed by enhanced chemoluminescence (Supersignal West Pico Chemiluminescent Substrate, Thermo Scientific) and visualized on film (Amersham Hyperfilm ECL, GE Healthcare, Diegem, Belgium).

\section{Mimic transfections}

MiRIDIAN microRNA mimics (Thermo Scientific, EttenLeur, Netherlands) of hsa-miR-210-3p and hsa-miR-485$5 \mathrm{p}$ and miRIDIAN microRNA Mimic Negative Control \#1 (Thermo Scientific) were transfected in a final concentration of $50 \mathrm{nM}$ using DharmaFECT1 transfection reagent (Thermo Scientific) $24 \mathrm{~h}$ after cell seeding. Transfection efficiency was optimized to $>95 \%$ using fluorescent mimics.

\section{Cloning}

Fragments of the 3'UTR of HIF3 $\alpha$ (HIF3 $\alpha$-short: $817 \mathrm{bp}$ fragment, HIF3 $\alpha$-long: 3807 bp fragment) were PCR amplified from human genomic DNA (Promega, Leiden, The Netherlands) introducing a XhoI (5'-end) and a NotI site (3'-end). The PCR products were cloned in $\mathrm{PCR}^{\circ}$-Blunt (Invitrogen), followed by a XhoI and NotI restriction and ligation in the psiCHECK ${ }^{\mathrm{m}}-2$ vector (Promega) behind a Renilla luciferase gene. The psiCHECK2 vector also contains a firefly luciferase gene, which was used for normalization. The resulting constructs are psiCHECK2/HIF3 $\alpha$-short and psiCHECK2/HIF3 $\alpha$-long. Site directed mutagenesis (QuickChange II XL, site directed mutagenesis kit, Agilent Technologies, Amsterdam, The Netherlands) was performed to mutate miR-210-3p and miR-485-5p target sites in the 3'UTR of HIF3 $\alpha$ in psiCHECK2/HIF3 $\alpha$-short (Additional file 1: Figure S1). Primer sequences used for cloning and mutagenesis are listed in Additional file 1: Table S1b and S1c.

\section{Luciferase assay}

PsiCHECK-2/HIF3 $\alpha$-short and psiCHECK2/HIF3 $\alpha$-long constructs were transfected using Fugene HD transfection reagent (Promega) $24 \mathrm{~h}$ after cell seeding, or when mimics were used, $24 \mathrm{~h}$ after miRNA mimic transfection, according to recommendations by the manufacturer. After 24 hours the cells were washed with PBS and lysed by Passive Lysis Buffer (Dual Luciferase ${ }^{\circledR}$ Reporter Assay System, Promega) for $30 \mathrm{~min}$ on a shaker platform. Lysates were transferred to white 96-wells microplates. Luciferase Assay Reagent II (Dual Luciferase ${ }^{\circledR}$
Reporter Assay System, Promega) was added, immediately followed by quantitation of the firefly luciferase activity on a luminometer (Aspekt Fluoroskan). Subsequently, Stop \& Glo ${ }^{\circledR}$ Reagent (Dual Luciferase ${ }^{\circledR}$ Reporter Assay System, Promega) was added to the mixture, immediately followed by quantitation of the Renilla luciferase activity. Relative luciferase signals of duplicates were averaged, values $(\mathrm{n}=3)$ were normalized, and average and standard deviations were calculated. Significant differences in luciferase activity were determined by twosample t-tests.

\section{Detection of HRE in miRNA promoter regions}

To determine whether the putative promoter regions of miR-216a-5p, miR-185-3p and miR-625-5p contain hypoxia responsive elements (HRE) we downloaded $600 \mathrm{bp}$ of 5' flanking sequences for each of the three miRNA genes from the Ensembl Genome Browser release 72 (http://www.ensembl.org). We scanned the flanking sequences for the presence of consensus HREs (A/GCGTG) and imperfect HREs.

\section{Results}

Hypoxia responsive miRNAs in soft tissue sarcoma cells

In order to examine the miRNA response to hypoxia in sarcomas, a panel of 12 soft tissue sarcoma cell lines was cultured for $0 \mathrm{~h}, 6 \mathrm{~h}, 24 \mathrm{~h}$ and $48 \mathrm{~h}$ under hypoxic (1\% oxygen) or normoxic (21\% oxygen) conditions. Exposure to hypoxic conditions was verified by the upregulation of HIF1 $\alpha$ protein levels, which is one of the earliest markers of hypoxia. HIF1 $\alpha$ protein, being degraded under normoxic conditions, is stabilized during hypoxia. As expected, HIF1 $\alpha$ protein levels were significantly increased upon hypoxic stress (Figure 1A). In all 12 cell lines examined peak HIF1 $\alpha$ levels were observed at the $6 \mathrm{~h}$ time point which decreased after $24 \mathrm{~h}$ and $48 \mathrm{~h}$ of hypoxia as shown for 5 representative cell lines (Figure 1A). As a consequence of HIF1 $\alpha$ upregulation, the transcription of specific HIF1 target genes like CA9 and VEGFA was slightly induced after $6 \mathrm{~h}$ and further increased after 24-48 $\mathrm{h}$ of hypoxia, as shown for 5 representative cell lines (Figure 1B, C). Note that in particular the increase in CA9 varies considerably between cell lines. The carbonic anhydrase CA9 is a member of a zinc metalloenzyme family that catalyses the reversible hydration of carbon dioxide to carbonic acid [35,36]. CA9 is a transmembrane protein which is found overexpressed in numerous tumor types and induced under hypoxic conditions. Similarly HIF $1 \alpha$ stimulates the expression of the vascular endothelial growth factor (VEGFA) which functions as an signal mediating vasculogenesis and angiogenesis [37].

Next, the miRNA expression profile was analyzed using microarrays containing $\mathrm{LNA}^{\mathrm{tm}}$ oligonucleotide capture 


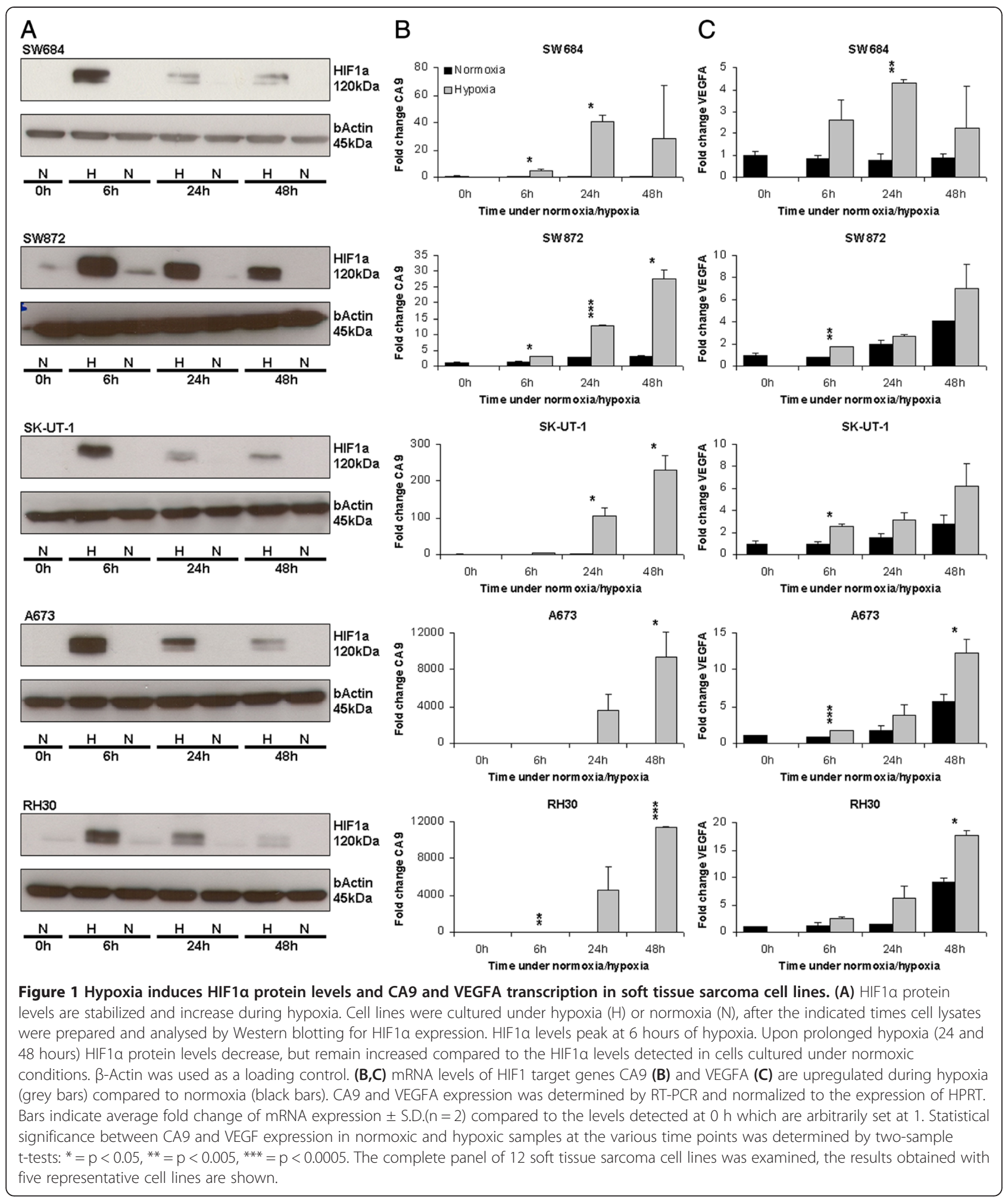

probes capable of detecting 725 human miRNAs. Since HIF1 target genes were clearly induced after $24 \mathrm{~h}$ of hypoxia, miRNA expression levels of cell lines that were cultured for $24 \mathrm{~h}$ under normoxic or hypoxic conditions were compared. Unsupervised hierarchical clustering based on the miRNA expression profiles of 407 miRNAs grouped the cell lines on cell type rather than on exposure to hypoxia (Figure 2A), which implies that the 

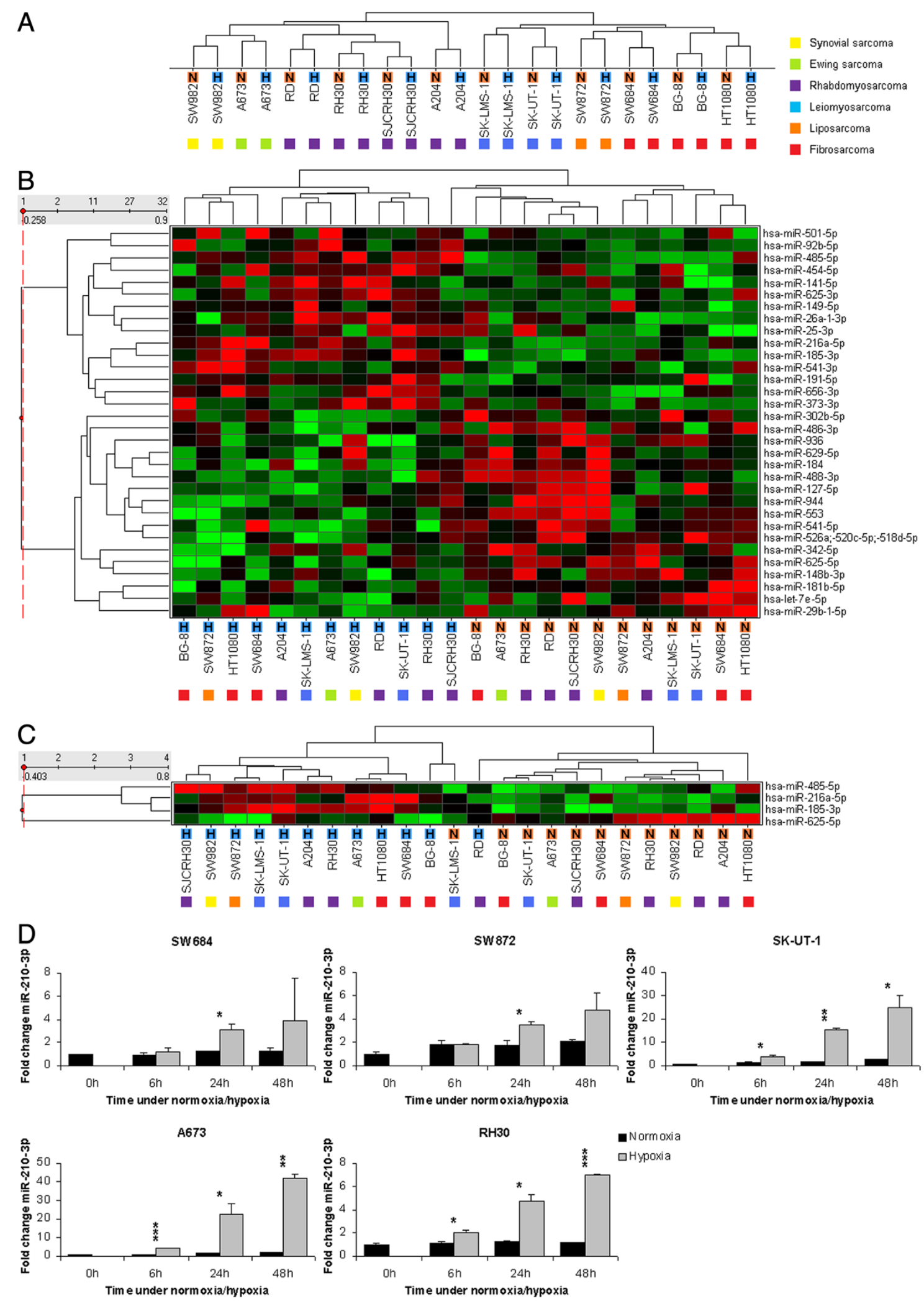

Figure $\mathbf{2}$ (See legend on next page.) 
(See figure on previous page.)

Figure 2 Hypoxia induces changes in miRNA expression. (A) Unsupervised hierarchical clustering using miRNA expression data (407 miRNAs) of hypoxic $(\mathrm{H})$ and normoxic $(\mathrm{N})$ cell line samples does not discriminate the hypoxic and normoxic samples. The hypoxic samples cluster together with their normoxic counterparts. (B) The most significant differentially expressed miRNAs (two-sample $t$-test, $p<0.05$ ) between cell lines that were cultured under normoxic and hypoxic conditions are used for a supervised hierarchical clustering. The expression of these 32 miRNAs can distinguish hypoxic from normoxic sarcoma cell line samples. (C) The four most significant $(P<0.001)$ differentially expressed miRNAs (miR-485-5p, miR-216a-5p, miR-185-3p and miR-625-5p) discriminate sarcoma cell lines that were cultured under normoxic conditions from those cultured under hypoxic conditions in a supervised hierarchical clustering. (D) MiR-210-3p is upregulated during hypoxia. RT-PCR was used to determine miR-210-3p levels in normoxic (black bars) and hypoxic (grey bars) samples from five representative sarcoma cell lines. Expression is normalized against RNU43 expression. Bars indicate average expression fold change \pm S.D. $(n=2)$ of miR-210-3p compared to the expression at 0 h. Statistical significance between expression in normoxic and hypoxic samples at a time point were determined by two-sample t-tests: ${ }^{*}=p<0.05,{ }^{* *}=p<0.005,{ }^{* *}=p<0.0005$. The different cell lines are indicated by a color code that identifies their tumor of origin: with synovial sarcoma (yellow); Ewing sarcoma (green); rhabdomyosarcoma (purple); leiomyosarcoma (blue); liposarcoma (orange) and fibrosarcoma (red).

changes in miRNA expression due to hypoxia are relatively minor. One major cluster branch contains the rhabdomyosarcoma cell lines and the synovial sarcoma cell line, the other branch contains the other cell lines (leiomyosarcoma, liposarcoma and fibrosarcoma cell lines). Supervised hierarchical clustering using the 32 most differentially expressed miRNAs $(\mathrm{p}<0.05$; Additional file 1: Table S2) between cell lines exposed to hypoxia or normoxia clearly separated the hypoxic from the normoxic samples (Figure 2B). Fifteen miRNAs were upregulated during hypoxia, while 17 miRNAs were downregulated. The SJCRH30 rhabdomyosarcoma cell line cultures under hypoxia was the only sample that misclustered, which indicates that the hypoxia induced miRNA response in this cell line was apparently weak. The top four differentially expressed miRNAs $(\mathrm{p}<0.001)$ consisted of miR-185-3p, miR-485-5p, miR-216a-5p and miR-625-5p (Figure 2C; Additional file 1: Table S2). Only miR-625-5p was downregulated in most hypoxic samples, whereas the other three miRNAs were predominantly upregulated. MiR210-3p, a commonly found hypoxia responsive miRNA (HRM), was not reliably detected on our microarray platform. Therefore the miR-210-3p expression in normoxic and hypoxic sarcoma cell line samples was separately determined by qPCR, which revealed a significant upregulation of miR-210-3p in all cell lines after $24 \mathrm{~h}$ of hypoxia (Figure 2D).

\section{HIF3a transcripts are expressed and upregulated under hypoxia in sarcoma cell lines}

Candidate target genes for the most differentially expressed miRNAs identified in the microarray analysis were predicted using TargetScanHuman 6.2 (http://www. targetscan.org/) [38]. When we focused on genes known to play a role in the hypoxic response it was noted that miR-485-5p has as much as 11 potential binding sites in the 3'UTR of HIF3 $\alpha$, the less studied member of the family of hypoxia inducible factors. Also miR-210-3p has a single putative binding site in this transcript (Figure 3A). Several human HIF $3 \alpha$ transcripts exist due to alternative splicing, coding for different HIF3 $\alpha$ isoforms [5-7]. According to the Ensembl Genome Browser release 72 (http://www. ensembl.org) the HIF3 $\alpha$ transcript variants 003 and 201 (consistent with HIF3 $\alpha$ transcription variant 1, 2 and 3 according to GenBank (http://www.ncbi.nlm.nih.gov/ genbank)) contain a long 3'UTR of 3811 bp which includes the potential miR-210-3p and miR-485-5p binding sites. In order to determine whether these transcripts are expressed in our sarcoma cell line panel we used an adapted RT-PCR procedure involving an end-point PCR and specific primers located in the 3'UTR (primer sites are indicated in Figure 3B, primer sequences are listed in Additional file 1: Table S1a). HIF3 $\alpha$ transcripts containing a long 3'UTR harboring the mentioned miRNA binding sites could be detected in all cell lines and were upregulated in time under hypoxic conditions (Figure 3D).

\section{MiR-485-5p and miR-210-3p target HIF3a}

The effects of miR-210-3p and miR-485-5p overexpression on HIF3 $\alpha$, protein levels were examined by immunoblotting. The sarcoma cell lines SW872 (liposarcoma) and SKUT-1 (leiomyosarcoma) were transfected with mimics of miR-210-3p, miR-485-5p or a scrambled negative control. $48 \mathrm{~h}$ post-transfection the cells were exposed to hypoxia for $24 \mathrm{~h}$ to induce HIF3 $\alpha$. Figure $4 \mathrm{~A}$ clearly shows that overexpression of the miRNA mimics resulted in a reduced induction of HIF3 $\alpha$ when compared to the HIF $3 \alpha$ protein levels observed in cells transfected with a scrambled control mimic (mneg). The detected HIF3 $\alpha$ protein has a relative molecular weight of approximately $70 \mathrm{kDa}$ which is in line with the predicted molecular weight of the HIF3 $\alpha$ proteins encoded by the 003 or 201 HIF3 $\alpha$ transcript variants.

To demonstrate that during hypoxia HIF $3 \alpha$ is regulated by hypoxia responsive miRNAs, a short (HIF3 $\alpha$-short, $817 \mathrm{bp}$ ) and a long (HIF3 $\alpha$-long, $3807 \mathrm{bp}$ ) fragment of the HIF3 $\alpha$ 3'UTR (variants 003/201) (Figure 3C) were cloned in a psiCHECK2 luciferase reporter. The psiCHECK2/HIF3 $\alpha$-short construct encompassed the putative miR-210-3p binding site and the first miR-485-5p binding site. The psiCHECK $2 / \mathrm{HIF} 3 \alpha$-long construct included an additional 10 potential binding sites for 


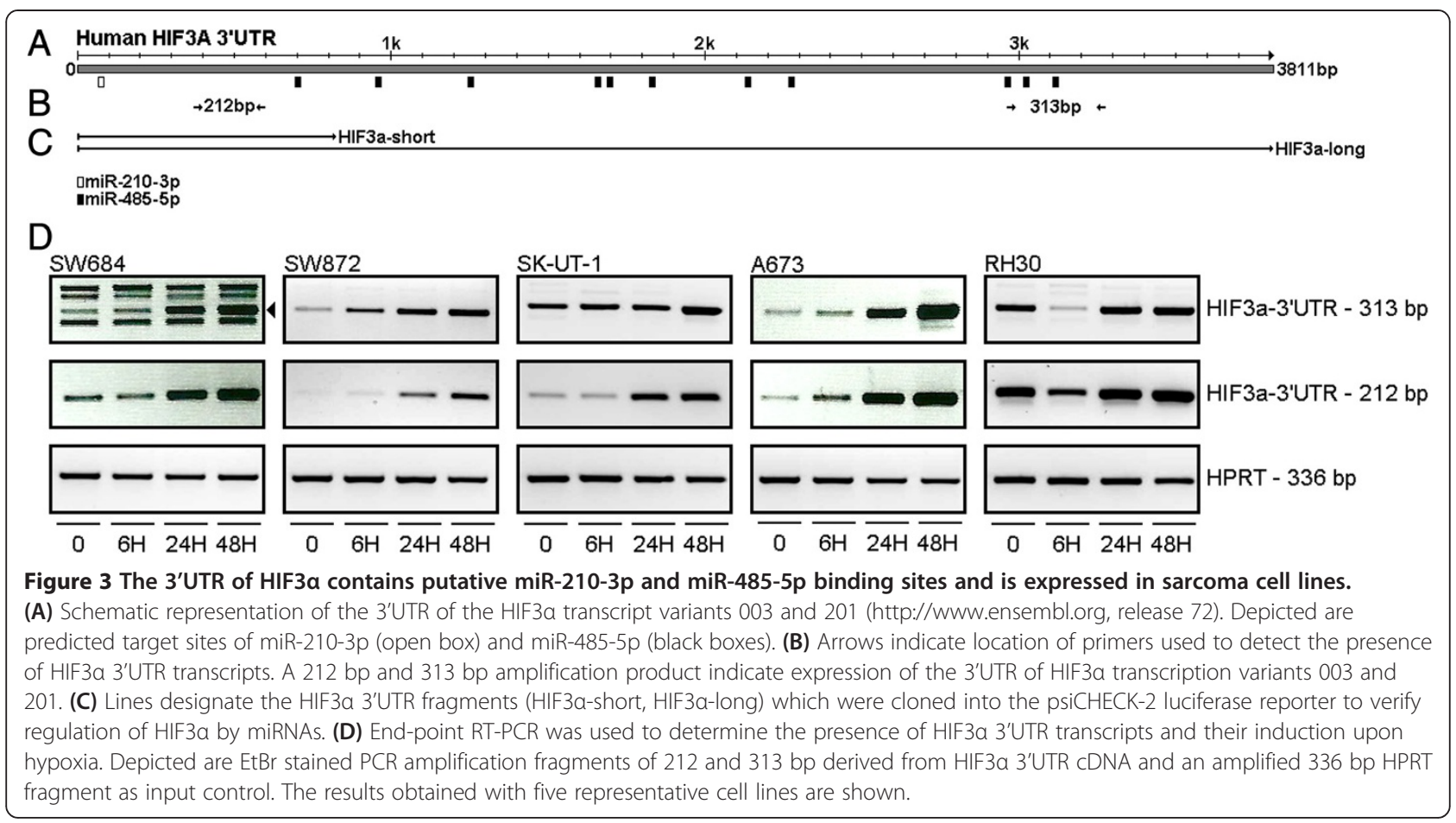

miR-485-5p. The SW872 an SK-UT-1 cell lines were transfected with the psiCHECK $2 / H I F 3 \alpha$-short and psiCHECK $2 /$ HIF $3 \alpha$-long constructs. The next day the cells were exposed to hypoxia for $24 \mathrm{~h}$, after which the luciferase activity in cell lysates was determined. Luciferase activity in SW872 hypoxic lysates was reduced to $57 \%$ and $65 \%$ in the HIF $3 \alpha$-short and HIF $3 \alpha$-long transfectants, respectively, when compared to the levels seen at normoxic circumstances (Figure 4B, left panel). In the hypoxic SK-UT-1 lysates the luciferase activity was decreased to $79 \%$ and $67 \%$ in the HIF $3 \alpha$-short and HIF3 $\alpha$-long transfectants, respectively (Figure $4 \mathrm{~B}$, right panel). These results indicate that during $24 \mathrm{~h}$ hypoxia the 3'UTR of HIF $3 \alpha$ is targeted, most likely by hypoxia responsive miRNAs, causing a reduction of the luciferase activity.

To examine whether downregulation of HIF3 $\alpha$ is mediated by miR-210-3p and/or miR-485-5p we transfected miRNA mimics for miR-210-3p and miR-485-5p in SW872 and SK-UT-1 cells, after $24 \mathrm{~h}$ followed by the transfection of the psiCHECK2/HIF3 $\alpha$ 3'UTR luciferase reporter constructs. Compared to the scrambled negative control (mneg), miR-210-3p overexpression decreased the luciferase activity to $36 \%$ and $41 \%$ in SW872 (Figure $4 C$, left panel) and 37\% and 43\% in SK-UT-1 (Figure 4C, right panel) in the HIF3 $\alpha$-short and HIF3 $\alpha$-long transfectants respectively. MiR-485-5p overexpression reduced the luciferase activity to $61 \%$ in the HIF $3 \alpha$-short construct in the SW872 cell line. When ten additional putative binding sites for miR-485-5p were introduced in the HIF3 $\alpha$ long transfectant, the luciferase activity dropped to $45 \%$
(Figure 4C, left panel). Overexpression of miR-485-5p decreased luciferase activity to $52 \%$ in SK-UT-1 cells transfected with psiCHECK $2 / \mathrm{HIF} 3 \alpha$-short and further reduced luciferase activity to $24 \%$ in the HIF3 $\alpha$-long transfectants (Figure 4C, right panel).

To prove whether the regulation of HIF3 $\alpha$ is due to direct binding of miR-210-3p and miR-485-5p to target sites in the 3'UTR, the predicted binding sites were mutated to prevent miRNA binding (Additional file 1: Figure S1). Since the regulatory effect of the single miR485-5p site present in the HIF3 $\alpha$-short construct was greater than the effect of the additional miR-485-5p binding sites present in the HIF3 $\alpha$-long construct, only the miR-485-5p target site in the HIF3 $\alpha$-short construct was mutated. The presence of a mutated miR-210-3p binding site significantly increased (SW872) or restored (SK-UT-1) luciferase activity (Figure 4D). Mutation of the miR-485-5p target site did not affect luciferase activity in SW872 cells and restored luciferase activity to some extent in the SK-UT-1 cells. We conclude that miR-210-3p directly regulates HIF3 $\alpha$ whereas the regulation observed with miR-485-5p is primarily due to an indirect effect. However, we cannot rule out that direct regulation of HIF3 $\alpha$ does occur mediated by one or more of the additional miR-485-5p binding sites in the HIF $3 \alpha$ 3'UTR.

\section{Discussion}

STS, like all solid tumors, can present with hypoxic areas, a state which is associated with disease progression and 


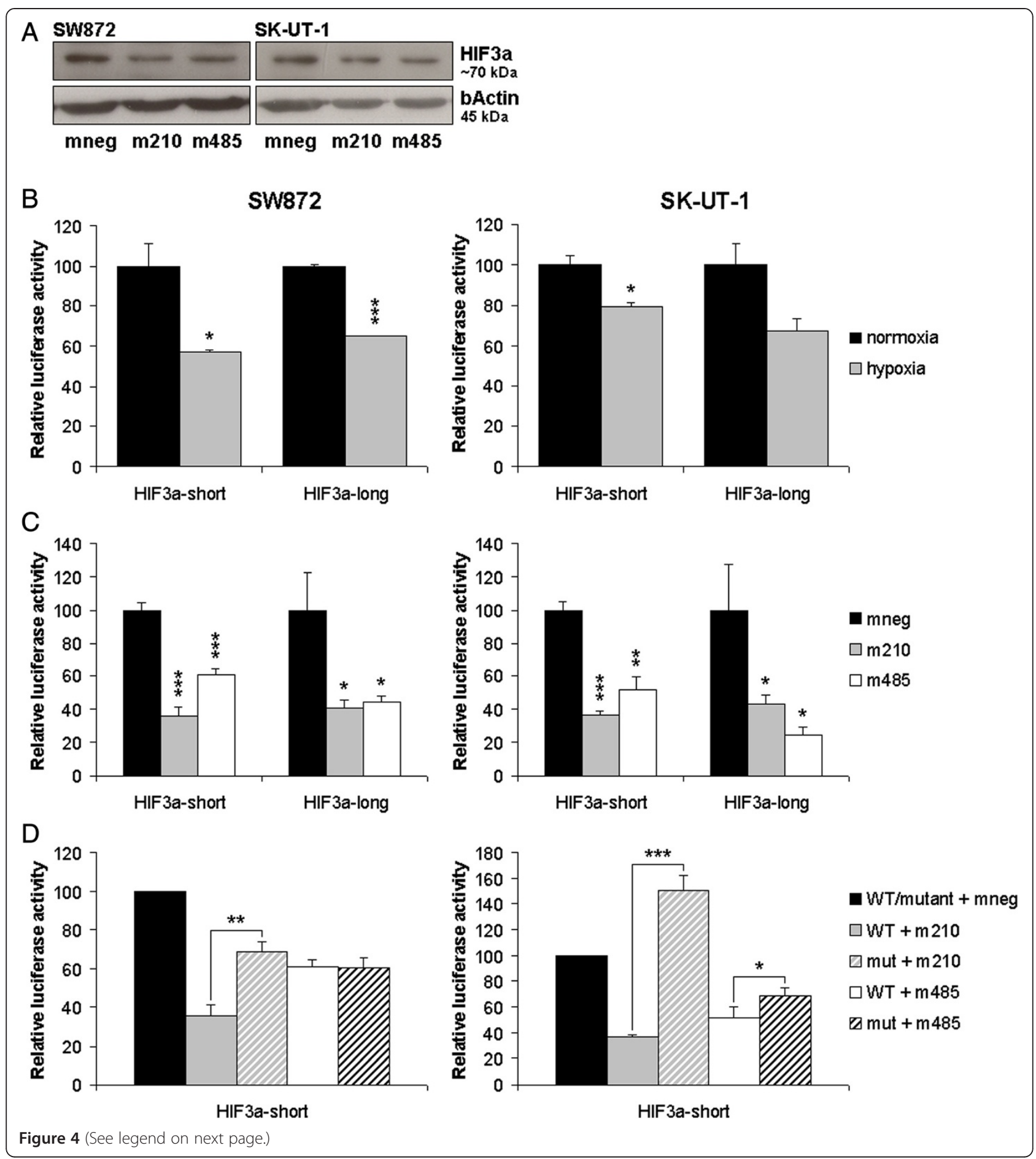




\section{(See figure on previous page.)}

Figure 4 HIF3a is regulated by miR-210-3p and miR-485-5p. (A) MiR-210-3p and miR-485-5p mimic overexpression reduce HIF3a protein induction under hypoxic conditions. The sarcoma cell lines SW872 and SK-UT-1 were transfected with mimics of miR-210-3p (m210), miR-485-5p (m485) and a scrambled negative control mimic (mneg). $48 \mathrm{~h}$ post-transfection cells were cultured under hypoxic conditions (1\% $\mathrm{O}_{2}$ ) for $24 \mathrm{~h}$. Subsequently total protein lysates were prepared and analysed by Western blotting for HIF3a protein expression. $\beta$-Actin is used as a loading control. (B) Hypoxia responsive miRNAs target HIF3a 3'UTR. SW872 and SK-UT-1 cell lines were transfected with psiCHECK 2 constructs containing short and long 3'UTR fragments of HIF3a. $24 \mathrm{~h}$ later the cells were exposed to hypoxia for $24 \mathrm{~h}$. Bars indicate average luciferase activity \pm SD $(n=3)$ measured in hypoxic cell lysates relative to the luciferase activity in normoxic cell lysates which is arbitrarily set at 100 . (C) MiR-210-3p and miR-485-5p regulate HIF3a. SW872 and SK-UT-1 cell lines were transfected with mimics of miR-210-3p (m210), miR-485-5p (m485) or a scrambled control mimic (mneg) followed after $24 \mathrm{~h}$ by a transfection with psiCHECK 2 constructs containing short and long fragments of the HIF3a 3 'UTR. Bars indicate average luciferase activity \pm SD $(n=3)$ measured in cell lysates after 24 h. (D) MiR-210-3p and miR-485-5p regulate HIF3a. SW872 and SK-UT-1 cell lines were transfected with mimics of miR-210-3p (m210), miR-485-5p (m485) or a scrambled control mimic (mneg) followed, after 24 h, by a transfection with a psiCHECK 2-HIF3a-short construct containing either wild-type (WT) or mutated (mut) miR-210-3p and miR-485-5p binding sites. Bars indicate average luciferase activity \pm SD $(n=3)$ measured in cell lysates. Statistical significance was determined by two-sample t-tests: ${ }^{*}=p<0.05,{ }^{* *}=p<0.005,{ }^{* * *}=p<0.0005$.

bad prognosis $[14,15]$. To date, little is known about the involvement of miRNAs in the hypoxic response of STS. Greither et al. reported that the expression of miR-2103 , a well-known hypoxia responsive miRNA, is associated with poor survival in STS [39]. We identified 32 miRNAs that are deregulated upon hypoxia in a panel of 12 soft tissue sarcoma cell lines. Particularly, miR-185$3 \mathrm{p}, \mathrm{miR}-485-5 \mathrm{p}, \mathrm{miR}-216 \mathrm{a}-5 \mathrm{p}$ were significantly upregulated, while miR-625-5p was significantly downregulated. In addition we detected induction of miR-210-3p upon hypoxia using a RT-PCR procedure. In all cell lines examined, our array platform did not detect a significant upregulation of miR-210-3p expression upon hypoxia. In fact, expression levels detected were too low to be considered for subsequent analyses. This is most likely due to the fact that the LNA capture probe for miR-210-3p was not optimally designed. Exiqon varies both length and LNA contents of the capture probes to obtain a Tm normalized probe with appropriate affinity for its target miRNA. Although the design and composition of the capture probes are proprietary information we learned that Exiqon has redesigned the miR-210-3p capture probe in subsequent versions of the capture probe set. A subset of the deregulated miRNAs, i.e. miR-185-3p, miR191, miR-210-3p, miR-373 (upregulated), miR-148b, miR-181b and miR-342-5p (downregulated), was previously identified as hypoxia responsive miRNAs (HRM) in other studies involving different cancer types [40-43]. These miRNAs may be regarded as general responders to hypoxia. However the majority of miRNAs we detected has not been previously associated with hypoxia suggesting a cell-type specific miRNA response, as has been reported before $[25,44]$.

The molecular mechanisms responsible for miRNA deregulation in response to hypoxia are for a large part still unclear as is the precise role of each of the HRM in the hypoxia response. As the key response to hypoxic conditions is the stabilization of HIF1, HRMs can be regulated by HIF-dependent or, alternatively, by HIF- independent mechanisms (reviewed in $[44,45]$ ). Some HRMs, such as miR-210-3p, contain hypoxia responsive elements (HREs) in their promoter region and are directly regulated by the HIF1 transcription factor in response to hypoxia $[26,46,47]$. Although HIF1 is generally known as a transcriptional activator, it can also function as a transcriptional repressor [48], which could account for the downregulated miRNAs under hypoxic conditions. Another HIF-dependent mechanism by which hypoxia responsive miRNAs are regulated is via a HIF1 induced transcription factor, such as TWIST, which induces miR-10b expression [49]. A HIF-independent mechanism involved in the regulation of HRMs is e.g. the induction of Akt2 upon hypoxia, which in turn upregulates miR-21 [50]. Also deregulation of the miRNA biogenesis during hypoxia could contribute to altered miRNA expression levels. Recently it was reported that hypoxia enhanced the association between EGFR and Ago2, resulting in increased Ago2-phosphorylation and reduced binding of Dicer to Ago2, thereby inhibiting miRNA processing [51]. In contrast, in another study hypoxia did not alter the expression of key miRNA machinery proteins (i.e. Drosha, Exp5, Dicer, Ago2 and DP103) in human trophoblasts [52]. In order to determine whether our top hypoxia responsive miRNAs (miR-185-3p; miR-485-5p; miR-216a-5p and miR-625$5 p)$ contain HREs in their putative promoter region we screened $600 \mathrm{bp}$ flanking sequences upstream of the transcription start site of the primary miRNA. With the exception of miR-485-5p of which the gene resides in a densely packed miRNA cluster on chromosome 14, the genes for miR-185-3p, miR-216a-5p and miR-625-5p are not clustered. No consensus HRE (A/GCGTG) could be detected upstream of miR-625-5p (which was downregulated during hypoxia), whereas miR-216a-5p contains a 'ACGTGC'(position -42 to -37) and miR-185-3p contains a 'CCGTG'(position -305 to -301). Although the latter HRE does not perfectly match the consensus HRE sequence, imperfect HREs have been found to be functional 
$[11,53,54]$. Therefore it is possible that miR-216a-5p and miR-185-3p are regulated by HIF1.

Since miR-210-3p is considered a general responder to hypoxia irrespective of cell-type and exact hypoxic conditions, its function is thought to be universal. MiR-210$3 p$ has been demonstrated to have a role in e.g. cell proliferation, angiogenesis, apoptosis, DNA repair and mitochondrial metabolism (reviewed in [55-57]). The function of other, less commonly deregulated HRMs is poorly understood, but these miRNAs are likely to have a cell-type specific function. Not much is known about miR-485-5p. This miRNA was downregulated in ependymomas [58] and suppressed dendritic spine development in rats [59]. Furthermore miR-485-5p was downregulated in Alzheimers disease [60] and malignant serous ovarian tumors, and correlated with FIGO grade in the latter [61]. Computational analysis predicted as much as eleven putative miR-485-5p binding sites in the 3'UTR of HIF3 $\alpha$. Also miR-210-3p has a potential binding site in the 3'UTR of this member of the family of hypoxia inducible factors. Note that there are only two HIF3 $\alpha$ transcripts (variants 003 and 201) listed (http://www. ensembl.org; release 72) that habor a 3'UTR long enough to encompass all miR-485-5p binding sites in addition to the miR-210-3p site. At least two other HIF3 $\alpha$ transcripts that contain a smaller 3'UTR (478 bp in variant 006 and $287 \mathrm{bp}$ in variant 007) also contain the miR-210-3p binding site suggesting that the HIF3 $\alpha$ isoforms they encode may be controlled by miR-210-3p. We demonstrated that HIF3 $\alpha$ is regulated by miR-210$3 \mathrm{p}$ and in an indirect fashion by miR-485-5p. We also showed that HIF3 $\alpha$ mRNA levels are induced upon hypoxia as expected of a hypoxia inducible factor. Under the same conditions, however, the expression of hypoxia responsive miRNAs like miR-210-3p and miR-485-5p is upregulated that affect $\mathrm{HIF} 3 \alpha$ protein expression. We postulate that miRNAs help to fine-tune HIF $\alpha \alpha$ protein expression and in this way regulate the cellular hypoxic response. They can do so by affecting the translation of specific HIF3 $\alpha$ transcripts, however, we cannot rule out that part of the regulation takes place via HIF3 $\alpha$ mRNA degradation. Although HRMs targeting HIF3 $\alpha$ has never been documented before, miRNA regulation of HIFs is not uncommon: miR-155 [46], miR-424 [28], and the miR-17-92 cluster [30] are known to target HIF1 $\alpha$. Thus HIFs can induce the expression of miRNAs, and in turn, miRNAs can also target HIFs.

Our understanding of the regulation of HIF3 $\alpha$ and its role in the hypoxic response is still rather limited. Reports in the literature are sometimes contradictory or difficult to compare as they focus on different HIF3 $\alpha$ splice variants in different cell types. It is clear that HIF3 $\alpha$ can be regulated at different levels. Transcription of HIF3 $\alpha$ can be induced by HIF via HREs in the promoter region $[5,7,11]$. This probably accounts for the increased HIF $3 \alpha$ mRNA expression upon hypoxia. In addition HIF $3 \alpha$ can be regulated at the protein level. HIF $1 \alpha$ and HIF $2 \alpha$ contain an oxygen dependent degradation domain (ODDD), which harbors two conserved prolines that can be hydroxylated by prolyl hydroxylases (PHDs) in presence of oxygen. This marks the proteins for proteasomal degradation via the von Hippel-Lindau (VHL) E3 ubiquitin ligase complex. It was postulated that HIF $3 \alpha$, in contrast with HIF $1 \alpha$ and HIF $2 \alpha$, is not regulated at the level of protein stability, since the longer HIF $3 \alpha$ transcripts miss part of the ODDD and the shorter isoforms lack the entire ODDD. This renders them less prone to hydroxylation and subsequent proteasomal degradation [11]. However, other studies showed that the remaining proline residue in the ODDD of HIF $3 \alpha$ transcripts is targeted by VHL and subjected to proteasomal degradation in an oxygen dependent manner [5,6]. Besides transcriptional regulation of HIF $3 \alpha$ by HIF1 and oxygen dependent degradation of HIF3 $\alpha$ proteins, we provide evidence for an additional layer of regulation of $\mathrm{HIF} 3 \alpha$, i.e. miRNAs that act on the translational level. These different mechanisms can complement one another in fine tuning HIF3 $\alpha$ expression. This may be critical because of the versatile role HIF3 $\alpha$ plays in the hypoxic response.

None of the HIF3 $\alpha$ variants are likely to act as potent transcription factors, since they lack a C-terminal transactivation domain. However, they can have an effect on HRE-driven gene expression, depending on the level of HIF $\beta[5,8,10]$. When HIF $\beta$ is not limiting, it will dimerize with HIF $1 \alpha$, HIF $2 \alpha$ and HIF3 $\alpha$ to induce a subset of hypoxia regulated genes. HIF $1 \alpha / \operatorname{HIF} \beta$ and HIF $2 \alpha$ / HIF $\beta$ complexes will associate with HRE sequences, while the HIF $3 \alpha /$ HIF $\beta$ complexes likely bind a response element different from the canonical HRE, to maximize hypoxia induced gene expression [5]. When HIF $\beta$ is limiting, HIF $3 \alpha$ will either compete with HIF1 $\alpha$ and HIF $2 \alpha$ for binding with HIF $\beta$ [8], or HIF3 $\alpha$ will associate with HIF $1 \alpha$ and HIF $2 \alpha[5,10]$, both resulting in decreased capability to bind HRE sequences and diminished transcription of HIF target genes. As such, HIF3 $\alpha$ splice variants will not act as global regulators of gene expressions, but may modulate specific genes in a cell type dependent manner $[5,11]$.

\section{Conclusion}

In conclusion, this study describes, in addition to miR210-3p, a new panel of HRMs in hypoxic sarcoma cells. In turn, two of these HRMs, i.e. miR-210-3p and miR$485-5 \mathrm{p}$, regulate $\mathrm{HIF} 3 \alpha$ in a direct or indirect fashion, respectively. Fine-tuning of HIF3 $\alpha$ expression is of great importance for the hypoxic response, since HIF3 $\alpha$ affects HIF1/2-induced gene expression. Keeping these negative 
feedback loops under tight control enables the cells to adapt to hypoxic conditions. Deregulation of these mechanisms, e.g. by therapeutic modulation of levels of miRNAs that are important for the hypoxic response, may inhibit the adaptive potential of the cells, and reduce their resistance against radiation and systemic agents.

\section{Additional file}

Additional file 1: Table S1. Primers used for PCR and cloning. (A)
Primers used for end-point RT-PCRs of HIF3a $3^{\prime} U$ UTR fragments, resulting
in amplification products of 212 bp (Fw/Rv1) and 313 bp (Fw/Rv2).
Amplification of HPRT (product of 335 bp) was used as input control. (B)
Primers used for cloning HIF3a-short and HIF3a-long $3^{\prime} U T R$ constructs.
(C) Primers used for site mutagenesis of predicted miR-485-5p and
miR-210-3p binding sites in HIF3a-short $3^{\prime} U T R$ constructs. Table S2
Differentially expressed miRNAs ( $p<0.05$ ) between cell lines that were
cultured under hypoxic and normoxic conditions. P-values of two-sample
t-test as well as fold change in miRNA expression and miRNA genomic
locations are indicated. False Discovery Rate (FDR) for the top four
miRNAs are: hsa-miR-185-3p (FDR 0.002893); hsa-miR-485-5p
(FDR 0.004466); hsa-miR-216a-5p (FDR 0.068687) and hsa-miR-625-5p
(FDR 0.112324). Figure S1 Predicted $3^{\prime} U T R$ target sites in HIF3a for
miR-210-3p and miR-485-5p and the mutations that have been generated
in the target site sequence where the miRNA seed sequence (bold) binds.
The wild-type (WT) and mutated (mut) sites in HIF3a-short are shown.
The vertical lines represent possible base pairing between miRNA and
3'UTR target site, and the x's indicate abrogated base pairing where
nucleotides are mutated (red). The resulting mutated $3^{\prime} U T R$ fragments
were cloned into the psiCHECK-2 luciferase reporter.

\section{Abbreviations}

HIF: hypoxia inducible factor; HRE: hypoxia responsive elements; HRM: hypoxia responsive miRNA; LNA: locked nucleic acid; miRNA: microRNA; qPCR: quantitative polymerase chain reaction; STS: soft tissue sarcomas; 3'UTR: 3'untranslated region.

\section{Competing interests}

The authors declare they have no competing interests.

\section{Authors' contributions}

CG, SS, JV, EW conceived the study. CG, EW, SS, RM, JV were involved in the design and coordination of the study. CG, PK, JR, MJ and NM performed qPCR, end-point PCR and Western blotting experiments. CG, WIJ, MJ carried out miRNA expression profiling CG, NM, EW participated in cloning experiments and luciferase reporter assays. CG, PK, WIJ, SS, RM, JV and EW drafted the manuscript. All authors read and approved the final version of the manuscript.

\section{Acknowledgements}

We thank dr. A. Carnero, dr. M. Debiec-Rychter and dr. L. Alberti for providing cell lines. This study was funded by EC FP6 CONTICANET network of excellence (LSHC-CT-2005-018806) from the European Commission.

\section{Author details \\ ${ }^{1}$ Department of Medical Oncology, Erasmus University Medical Center - Erasmus MC Cancer Institute, Rotterdam, the Netherlands. ${ }^{2}$ Center for Biomics, Erasmus University Medical Center, Rotterdam, the Netherlands. ${ }^{3}$ Department of Medical Oncology, Erasmus MC Cancer Institute, Erasmus University Medical Center, Rm Be422, Wytemaweg 80, 3015 CN Rotterdam, the Netherlands.}

Received: 2 September 2013 Accepted: 29 May 2014 Published: 13 June 2014

\section{References}

1. Harris AL: Hypoxia-a key regulatory factor in tumour growth. Nat Rev Cancer 2002, 2(1):38-47.
2. Wang GL, Semenza GL: General involvement of hypoxia-inducible factor 1 in transcriptional response to hypoxia. Proc Natl Acad Sci U S A 1993, 90(9):4304-4308.

3. Ema M, Taya S, Yokotani N, Sogawa K, Matsuda Y, Fujii-Kuriyama Y: A novel bHLH-PAS factor with close sequence similarity to hypoxia-inducible factor 1alpha regulates the VEGF expression and is potentially involved in lung and vascular development. Proc Natl Acad Sci U S A 1997, 94(9):4273-4278.

4. Hu CJ, Wang LY, Chodosh LA, Keith B, Simon MC: Differential roles of hypoxia-inducible factor 1alpha (HIF-1alpha) and HIF-2alpha in hypoxic gene regulation. Mol Cell Biol 2003, 23(24):9361-9374.

5. Heikkila M, Pasanen A, Kivirikko Kl, Myllyharju J: Roles of the human hypoxia-inducible factor (HIF)-3alpha variants in the hypoxia response. Cell Mol Life Sci 2011, 68(23):3885-3901.

6. Maynard MA, Qi H, Chung J, Lee EH, Kondo Y, Hara S, Conaway RC, Conaway JW, Ohh M: Multiple splice variants of the human HIF-3 alpha locus are targets of the von Hippel-Lindau E3 ubiquitin ligase complex. J Biol Chem 2003, 278(13):11032-11040.

7. Pasanen A, Heikkila M, Rautavuoma K, Hirsila M, Kivirikko Kl, Myllyharju J: Hypoxia-inducible factor (HIF)-3alpha is subject to extensive alternative splicing in human tissues and cancer cells and is regulated by HIF-1 but not HIF-2. Int J Biochem Cell Biol 2010, 42(7):1189-1200.

8. Hara S, Hamada J, Kobayashi C, Kondo Y, Imura N: Expression and characterization of hypoxia-inducible factor (HIF)-3alpha in human kidney: suppression of HIF-mediated gene expression by HIF-3alpha. Biochem Biophys Res Commun 2001, 287(4):808-813.

9. Maynard MA, Evans AJ, Hosomi T, Hara S, Jewett MA, Ohh M: Human HIF-3alpha4 is a dominant-negative regulator of HIF-1 and is down-regulated in renal cell carcinoma. FASEB J 2005, 19(11):1396-1406.

10. Maynard MA, Evans AJ, Shi W, Kim WY, Liu FF, Ohh M: Dominant-negative HIF-3 alpha 4 suppresses VHL-null renal cell carcinoma progression. Cell Cycle 2007, 6(22):2810-2816.

11. Tanaka T, Wiesener M, Bernhardt W, Eckardt KU, Warnecke C: The human HIF (hypoxia-inducible factor)-3alpha gene is a HIF-1 target gene and may modulate hypoxic gene induction. Biochem J 2009, 424(1):143-151.

12. Airley RE, Phillips RM, Evans AE, Double J, Burger AM, Feibig HH, West CM, Stratford IJ: Hypoxia-regulated glucose transporter glut-1 may influence chemosensitivity to some alkylating agents: results of EORTC (first translational award) study of the relevance of tumour hypoxia to the outcome of chemotherapy in human tumour-derived xenografts. Int J Oncol 2005, 26(6):1477-1484.

13. Hockel M, Schlenger K, Aral B, Mitze M, Schaffer U, Vaupel P: Association between tumor hypoxia and malignant progression in advanced cancer of the uterine cervix. Cancer Res 1996, 56(19):4509-4515.

14. Brizel DM, Scully SP, Harrelson JM, Layfield LJ, Bean JM, Prosnitz LR, Dewhirst MW: Tumor oxygenation predicts for the likelihood of distant metastases in human soft tissue sarcoma. Cancer Res 1996, 56(5):941-943.

15. Nordsmark M, Hoyer M, Keller J, Nielsen OS, Jensen OM, Overgaard J: The relationship between tumor oxygenation and cell proliferation in human soft tissue sarcomas. Int J Radiat Oncol Biol Phys 1996, 35(4):701-708.

16. Wiemer EA: The role of microRNAs in cancer: no small matter. Eur $J$ Cancer 2007, 43(10):1529-1544.

17. Chen CZ: MicroRNAs as oncogenes and tumor suppressors. N Engl J Med 2005, 353(17):1768-1771.

18. Di Leva G, Croce CM: Roles of small RNAs in tumor formation. Trends Mol Med 2010, 16(6):257-267.

19. Lujambio A, Lowe SW: The microcosmos of cancer. Nature 2012, 482(7385):347-355.

20. Zhang B, Pan X, Cobb GP, Anderson TA: microRNAs as oncogenes and tumor suppressors. Dev Biol 2007, 302(1):1-12.

21. Li X, Wu Z, Fu X, Han W: A microRNA component of the neoplastic microenvironment: microregulators with far-reaching impact. Biomed Res Int 2013, 2013:762183.

22. Wentz-Hunter KK, Potashkin JA: The role of miRNAs as key regulators in the neoplastic microenvironment. Mol Biol Int 2011, 2011:839872.

23. Crosby ME, Devlin CM, Glazer PM, Calin GA, Ivan M: Emerging roles of microRNAs in the molecular responses to hypoxia. Curr Pharm Des 2009, 15(33):3861-3866.

24. Kulshreshtha R, Davuluri RV, Calin GA, Ivan M: A microRNA component of the hypoxic response. Cell Death Differ 2008, 15(4):667-671. 
25. Kulshreshtha R, Ferracin M, Negrini M, Calin GA, Davuluri RV, Ivan M: Regulation of microRNA expression: the hypoxic component. Cell Cycle 2007, 6(12):1426-1431

26. Kulshreshtha R, Ferracin M, Wojcik SE, Garzon R, Alder H, Agosto-Perez FJ, Davuluri R, Liu CG, Croce CM, Negrini M, Calin GA, Ivan M: A microRNA signature of hypoxia. Mol Cell Biol 2007, 27(5):1859-1867.

27. Cha ST, Chen PS, Johansson G, Chu CY, Wang MY, Jeng YM, Yu SL, Chen JS, Chang KJ, Jee SH, Tan C, Lin MT, Kuo ML: MicroRNA-519c suppresses hypoxia-inducible factor-1alpha expression and tumor angiogenesis. Cancer Res 2010, 70(7):2675-2685.

28. Ghosh G, Subramanian IV, Adhikari N, Zhang X, Joshi HP, Basi D, Chandrashekhar YS, Hall JL, Roy S, Zeng Y, Ramakrishnan S: Hypoxia-induced microRNA-424 expression in human endothelial cells regulates HIF-alpha isoforms and promotes angiogenesis. J Clin Invest 2010, 120(11):4141-4154.

29. Kelly TJ, Souza AL, Clish CB, Puigserver P: A hypoxia-induced positive feedback loop promotes hypoxia-inducible factor 1alpha stability through miR-210 suppression of glycerol-3-phosphate dehydrogenase 1-like. Mol Cell Biol 2011, 31(13):2696-2706.

30. Taguchi A, Yanagisawa K, Tanaka M, Cao K, Matsuyama Y, Goto H, Takahashi $\mathrm{T}$ : Identification of hypoxia-inducible factor- 1 alpha as a novel target for miR-17-92 microRNA cluster. Cancer Res 2008, 68(14):5540-5545.

31. Xu Q, Liu LZ, Qian X, Chen Q, Jiang Y, Li D, Lai L, Jiang BH: MiR-145 directly targets p70S6K1 in cancer cells to inhibit tumor growth and angiogenesis. Nucleic Acids Res 2012, 40(2):761-774.

32. Yamakuchi M, Lotterman CD, Bao C, Hruban RH, Karim B, Mendell JT, Huso D, Lowenstein CJ: P53-induced microRNA-107 inhibits HIF-1 and tumor angiogenesis. Proc Natl Acad Sci U S A 2010, 107(14):6334-6339.

33. Pothof J, Verkaik NS, van IJcken W, Wiemer EA, TA VT, van der Horst GT, Jaspers NG, van Gent DC, Hoeijmakers JH, Persengiev SP: MicroRNA-mediated gene silencing modulates the UV-induced DNA-damage response. EMBO J 2009 28(14):2090-2099.

34. Schmittgen TD, Livak KJ: Analyzing real-time PCR data by the comparative C(T) method. Nat Protoc 2008, 3(6):1101-1108.

35. Beasley NJ, Wykoff CC, Watson PH, Leek R, Turley H, Gatter K, Pastorek J, Cox GJ, Ratcliffe P, Harris AL: Carbonic anhydrase IX, an endogenous hypoxia marker, expression in head and neck squamous cell carcinoma and its relationship to hypoxia, necrosis, and microvessel density. Cancer Res 2001, 61(13):5262-5267.

36. Wykoff CC, Beasley NJ, Watson PH, Turner KJ, Pastorek J, Sibtain A, Wilson GD, Turley H, Talks KL, Maxwell PH, Pugh CW, Ratcliffe PJ, Harris AL: Hypoxia-inducible expression of tumor-associated carbonic anhydrases. Cancer Res 2000, 60(24):7075-7083.

37. Pugh CW, Ratcliffe PJ: Regulation of angiogenesis by hypoxia: role of the HIF system. Nat Med 2003, 9(6):677-684.

38. Lewis BP, Burge CB, Bartel DP: Conserved seed pairing, often flanked by adenosines, indicates that thousands of human genes are microRNA targets. Cell 2005, 120(1):15-20.

39. Greither T, Wurl P, Grochola L, Bond G, Bache M, Kappler M, Lautenschlager C, Holzhausen HJ, Wach S, Eckert AW, et al: Expression of microRNA 210 associates with poor survival and age of tumor onset of soft-tissue sarcoma patients. Int J Cancer 2012, 130(5):1230-1235.

40. Crosby ME, Kulshreshtha R, Ivan M, Glazer PM: MicroRNA regulation of DNA repair gene expression in hypoxic stress. Cancer Res 2009, 69 (3):1221-1229.

41. Guimbellot JS, Erickson SW, Mehta T, Wen H, Page GP, Sorscher EJ, Hong JS: Correlation of microRNA levels during hypoxia with predicted target mRNAs through genome-wide microarray analysis. BMC Med Genomics 2009, 2:15.

42. Hebert C, Norris K, Scheper MA, Nikitakis N, Sauk JJ: High mobility group A2 is a target for miRNA-98 in head and neck squamous cell carcinoma. Mol Cancer 2007, 6:5

43. Xu X, Jia R, Zhou Y, Song X, Wang J, Qian G, Ge S, Fan X: Microarray-based analysis: identification of hypoxia-regulated microRNAs in retinoblastoma cells. Int J Oncol 2011, 38(5):1385-1393.

44. Shen G, Li X, Jia YF, Piazza GA, Xi Y: Hypoxia-regulated microRNAs in human cancer. Acta Pharmacol Sin 2013, 34(3):336-341.

45. Nallamshetty S, Chan SY, Loscalzo J: Hypoxia: a master regulator of microRNA biogenesis and activity. Free Radic Biol Med 2013, 64:20-30

46. Bruning U, Cerone L, Neufeld Z, Fitzpatrick SF, Cheong A, Scholz CC, Simpson DA, Leonard MO, Tambuwala MM, Cummins EP, Taylor CT:
MicroRNA-155 promotes resolution of hypoxia-inducible factor 1alpha activity during prolonged hypoxia. Mol Cell Biol 2011, 31(19):4087-4096.

47. Huang $X$, Ding L, Bennewith KL, Tong RT, Welford SM, Ang KK, Story M, Le QT, Giaccia AJ: Hypoxia-inducible mir-210 regulates normoxic gene expression involved in tumor initiation. Mol Cell 2009, 35(6):856-867.

48. Chen KF, Lai YY, Sun HS, Tsai SJ: Transcriptional repression of human cad gene by hypoxia inducible factor-1alpha. Nucleic Acids Res 2005, 33(16):5190-5198.

49. Haque I, Banerjee S, Mehta S, De A, Majumder M, Mayo MS, Kambhampati S, Campbell DR, Banerjee SK: Cysteine-rich 61-connective tissue growth factor-nephroblastoma-overexpressed 5 (CCN5)/Wnt-1-induced signaling protein-2 (WISP-2) regulates microRNA-10b via hypoxia-inducible factor-1alpha-TWIST signaling networks in human breast cancer cells. J Biol Chem 2011, 286(50):43475-43485.

50. Polytarchou C, lliopoulos D, Hatziapostolou M, Kottakis F, Maroulakou I, Struhl K, Tsichlis PN: Akt2 regulates all Akt isoforms and promotes resistance to hypoxia through induction of miR-21 upon oxygen deprivation. Cancer Res 2011, 71(13):4720-4731.

51. Shen J, Xia W, Khotskaya YB, Huo L, Nakanishi K, Lim SO, Du Y, Wang Y, Chang WC, Chen CH, Hsu JL, Wu Y, Lam YC, James BP, Liu X, Liu CG, Patel DJ, Hung MC: EGFR modulates microRNA maturation in response to hypoxia through phosphorylation of AGO2. Nature 2013, 497(7449):383-387

52. Donker RB, Mouillet JF, Nelson DM, Sadovsky Y: The expression of Argonaute 2 and related microRNA biogenesis proteins in normal and hypoxic trophoblasts. Mol Hum Reprod 2007, 13(4):273-279.

53. Augstein A, Poitz DM, Braun-Dullaeus RC, Strasser RH, Schmeisser A: Cell-specific and hypoxia-dependent regulation of human HIF-3alpha: inhibition of the expression of HIF target genes in vascular cells. Cell Mol Life Sci 2011, 68(15):2627-2642

54. Makino Y, Uenishi R, Okamoto K, Isoe T, Hosono O, Tanaka H, Kanopka A Poellinger L, Haneda M, Morimoto C: Transcriptional up-regulation of inhibitory PAS domain protein gene expression by hypoxia-inducible factor 1 (HIF-1): a negative feedback regulatory circuit in HIF-1-mediated signaling in hypoxic cells. J Biol Chem 2007, 282(19):14073-14082.

55. Chan YC, Banerjee J, Choi SY, Sen CK: miR-210: the master hypoxamir. Microcirculation 2012, 19(3):215-223.

56. Devlin C, Greco S, Martelli F, Ivan M: miR-210: more than a silent player in hypoxia. IUBMB Life 2011, 63(2):94-100.

57. Ivan M, Harris AL, Martelli F, Kulshreshtha R: Hypoxia response and microRNAs: no longer two separate worlds. J Cell Mol Med 2008, 12(5A):1426-1431.

58. Costa FF, Bischof JM, Vanin EF, Lulla RR, Wang M, Sredni ST, Rajaram V, Bonaldo Mde F, Wang D, Goldman S, Tomita T, Soares MB: Identification of microRNAs as potential prognostic markers in ependymoma. PLoS One 2011, 6(10):e25114

59. Cohen JE, Lee PR, Chen S, Li W, Fields RD: MicroRNA regulation of homeostatic synaptic plasticity. Proc Natl Acad Sci U S A 2011 108(28):11650-11655.

60. Faghihi MA, Zhang M, Huang J, Modarresi F, Van der Brug MP, Nalls MA, Cookson MR, St-Laurent G 3rd, Wahlestedt C: Evidence for natural antisense transcript-mediated inhibition of microRNA function. Genome Biol 2010, 11(5):R56.

61. Kim TH, Kim YK, Kwon Y, Heo JH, Kang H, Kim G, An HJ: Deregulation of miR-519a, 153, and 485-5p and its clinicopathological relevance in ovarian epithelial tumours. Histopathology 2010, 57(5):734-743.

\section{doi:10.1186/1471-2407-14-429}

Cite this article as: Gits et al:: MicroRNA response to hypoxic stress in soft tissue sarcoma cells: microRNA mediated regulation of HIF3a. BMC Cancer 2014 14:429. 